\title{
Selective inhibition of mutant IDH1 by DS-1001b ameliorates aberrant histone modifications and impairs tumor activity in chondrosarcoma
}

\author{
Makoto Nakagawa ${ }^{1,2,3} \cdot$ Fumihiko Nakatani $^{3} \cdot$ Hironori Matsunaga ${ }^{4} \cdot$ Takahiko Seki $^{4} \cdot$ Makoto Endo $^{2}$. \\ Yoko Ogawara ${ }^{1}$ - Yukino Machida ${ }^{1}$ Takuo Katsumoto ${ }^{1}$ Kazutsune Yamagata ${ }^{1}$ - Ayuna Hattori ${ }^{1} \cdot$ Shuhei Fujita $^{1}$. \\ Yukiko Aikawa ${ }^{1} \cdot$ Takamasa Ishikawa $^{5} \cdot$ Tomoyoshi Soga $^{5} \cdot$ Akira Kawai $^{3} \cdot$ Hirokazu Chuman $^{6}$. \\ Nobuhiko Yokoyama $\left(^{2}\right.$. Suguru Fukushima ${ }^{2}$ Kenichiro Yahiro ${ }^{2}$. Atsushi Kimura ${ }^{2}$ E Eijiro Shimada ${ }^{2}$. \\ Takeshi Hirose $^{2} \cdot$ Toshifumi Fujiwara $^{2} \cdot$ Nokitaka Setsu $^{2} \cdot$ Yoshihiro Matsumoto $^{2} \cdot$ Yukihide Iwamoto $^{7}$. \\ Yasuharu Nakashima ${ }^{2} \cdot$ Issay Kitabayashi $^{1}$
}

Received: 20 December 2018 / Revised: 6 June 2019 / Accepted: 18 July 2019 / Published online: 12 August 2019

(c) The Author(s) 2019. This article is published with open access

\begin{abstract}
Chondrosarcoma is the second most common malignant bone tumor. It is characterized by low vascularity and an abundant extracellular matrix, which confer these tumors resistance to chemotherapy and radiotherapy. There are currently no effective treatment options for relapsed or dedifferentiated chondrosarcoma, and new targeted therapies need to be identified. Isocitrate dehydrogenase (IDH) mutations, which are detected in $~ 50 \%$ of chondrosarcoma patients, contribute to malignant transformation by catalyzing the production of 2-hydroxyglutarate (2-HG), a competitive inhibitor of $\alpha$-ketoglutaratedependent dioxygenases. Mutant IDH inhibitors are therefore potential novel anticancer drugs in IDH mutant tumors. Here, we examined the efficacy of the inhibition of mutant IDH1 as an antitumor approach in chondrosarcoma cells in vitro and in vivo, and investigated the association between the IDH mutation and chondrosarcoma cells. DS-1001b, a novel, orally bioavailable, selective mutant IDH1 inhibitor, impaired the proliferation of chondrosarcoma cells with IDH1 mutations in vitro and in vivo, and decreased 2-HG levels. RNA-seq analysis showed that inhibition of mutant IDH1 promoted chondrocyte differentiation in the conventional chondrosarcoma L835 cell line and caused cell cycle arrest in the dedifferentiated JJ012 cell line. Mutant IDH1-mediated modulation of SOX9 and CDKN1C expression regulated chondrosarcoma tumor progression, and DS-1001b upregulated the expression of these genes via a common mechanism involving the demethylation of $\mathrm{H} 3 \mathrm{~K} 9 \mathrm{me} 3$. DS-1001b treatment reversed the epigenetic changes caused by aberrant histone modifications. The present data strongly suggest that inhibition of mutant IDH1 is a promising therapeutic approach in chondrosarcoma, particularly for the treatment of relapsed or dedifferentiated chondrosarcoma.
\end{abstract}

Supplementary information The online version of this article (https:// doi.org/10.1038/s41388-019-0929-9) contains supplementary material, which is available to authorized users.

Issay Kitabayashi

ikitabay@ncc.go.jp

1 Division of Hematological Malignancy, National Cancer Center Research Institute, Tokyo, Japan

2 Department of Orthopaedic Surgery, Graduate School of Medical Sciences, Kyushu University, Fukuoka, Japan

3 Division of Musculoskeletal Oncology, National Cancer Center Hospital, Tokyo, Japan

\section{Introduction}

Chondrosarcoma is the second most common malignant bone neoplasm. It is characterized by the accumulation of malignant cells with chondrogenic features, leading to the

4 Oncology Laboratories, Daiichi Sankyo Co., Ltd, Tokyo, Japan

5 Institute for Advanced Biosciences, Keio University, Yamagata, Japan

6 Division of Orthopaedic Surgery, Katai Orthopaedic Internal Medicine Hospital, Fukuoka, Japan

7 Division of Orthopaedic Surgery, Kyushu Rosai Hospital, Fukuoka, Japan 
production of a cartilaginous matrix. Approximately $85 \%$ of chondrosarcomas are primary and of the conventional type [1]. Conventional chondrosarcoma, which includes central, peripheral, and periosteal subtypes according to the anatomical location of tumors, commonly develops in the medullary cavity and proliferates centrifugally. The remaining $15 \%$ of chondrosarcomas consist of clear cell, mesenchymal, and dedifferentiated subtypes. The most common skeletal sites are the bones of the pelvis, followed by the femur, humerus, and ribs [1]. Chondrosarcoma is generally resistant to chemotherapy and radiotherapy because of its low vascularity and the accumulation of extracellular matrix [2]. The standard treatment for chondrosarcoma is surgical resection of the tumor, and complete wide resection is necessary to achieve a curative effect because high-grade chondrosarcoma has high rates of local recurrence and distant metastasis [3, 4]. However, relapse and metastasis remain frequent in conventional chondrosarcomas, especially in spinal and pelvic tumors, because of the technical difficulties associated with wide resection, resulting in a poor prognosis [3]. Dedifferentiated chondrosarcoma, which develops in $10-15 \%$ of central chondrosarcomas, is characterized by the transition from a cartilage tumor to a more aggressive non-cartilage component containing features of osteosarcoma, fibrosarcoma, and high-grade spindle cell sarcoma. This type of tumor is characterized by a rapid change in clinical course and a dismal prognosis, with a 5 year survival of 10-25\% [4-6]. There are no effective treatments for relapsed, metastatic, or dedifferentiated chondrosarcomas, and the development of novel targeted therapies is urgently needed.

Heterozygous mutations in genes encoding isocitrate dehydrogenase $(I D H) 1$ and 2 are frequently detected in acute myeloid leukemia (AML), angioimmunoblastic T-cell lymphoma, glioma, and cholangiocarcinoma [7-10]. These mutations also occur in several benign and malignant cartilaginous tumors including conventional chondrosarcoma and dedifferentiated chondrosarcoma [11-13]. In chondrosarcoma, IDH mutations result in changes in specific amino acid residues, namely, R132 in IDH1 and R172 in IDH2 [12, 14, 15]. Mutant IDH catalyzes the formation of the oncometabolite D-2-hydroxyglutarate (D-2-HG), but not its enantiomer L-2-hydroxyglutarate (L-2-HG) [16], which competitively inhibits $\alpha$-ketoglutarate-dependent dioxygenases including epigenetic regulators (TETs and histone demethylases) and others (EGLN and collagen prolyl 4hydroxylases) [17-22]. The inhibitory effects of 2-HG lead to aberrant DNA and histone methylation [17-19], and the stabilization of hypoxia-inducible factor $1 \alpha$, which promote tumorigenesis [23]. The roles of mutant IDH in tumorigenesis have been analyzed extensively in vitro and in vivo. Mutant IDH increases the proliferation and represses the differentiation of cultured cells in vitro
[20, 24]. Expression of mutant IDH2 in the mouse mesenchymal cell line C3H10T1/2 causes aberrant DNA methylation and impairs differentiation [25]. Furthermore, IDH2 mutant cells develop into poorly differentiated sarcomas in xenograft models. These studies demonstrate that mutant IDH acts as an oncogene and can induce the formation of malignant tumors in vivo. Previous work from our group showed that mutation of IDH2 is critical for the development and maintenance of AML stem-like cells, and that targeting mutant IDH enzymes is a potential strategy for anticancer therapy [26].

Approximately $50 \%$ of conventional and dedifferentiated chondrosarcomas harbor IDH mutations [12]. The high prevalence of IDH mutations in chondrosarcoma suggests that these gain of function mutations are potential therapeutic targets for inoperable and metastatic tumors. However, the suppressive effect of mutant IDH1 inhibitors in chondrosarcoma is controversial [27, 28]. Namely, the mutant IDH1 inhibitor AGI-5198 does not impair the proliferation and migration of IDH1 mutated cell lines, although it markedly decreased D-2-HG levels, suggesting that cell growth in chondrosarcoma is independent from IDH mutations [27]. On the other hand, treatment with the drug at higher concentrations induced apoptosis and G2/M cell cycle arrest [28]. Several mutant IDH inhibitors have been developed [27-33], some of which are currently being tested in clinical trials for the treatment of various diseases including chondrosarcoma [34]. A mutant IDH1 inhibitor, AG-120, and a mutant IDH1/2 inhibitor, AG-881, are under clinical evaluation in phase I studies. In addition, AG-221, a mutant IDH2 inhibitor, is currently being tested in a phase I/ II trial [34]. However, whether mutant IDH is critical for the development and maintenance of chondrosarcoma cells remains unclear.

Here, we developed a novel, orally bioavailable, selective mutant IDH1 inhibitor, DS-1001b, which showed potent inhibitory activity against the IDH1 mutation. DS$1001 \mathrm{~b}$ is a clinically investigational drug and was used to investigate the role of mutant IDH1 in conventional or dedifferentiated-like chondrosarcoma cells. The aim of the present study was to evaluate the efficacy of inhibition of mutant IDH1 as a therapeutic approach in chondrosarcoma cells in vitro and in vivo, and to investigate the function of mutant IDH in chondrosarcoma cells.

\section{Results}

\section{DS-1001b impairs the proliferation of IDH1-mutated chondrosarcoma cell lines and decreases 2-HG levels}

A novel mutant IDH1 inhibitor, DS-1001b, was developed (Fig. 1a). DS-1001b strongly inhibited mutant IDH1 but not 
A

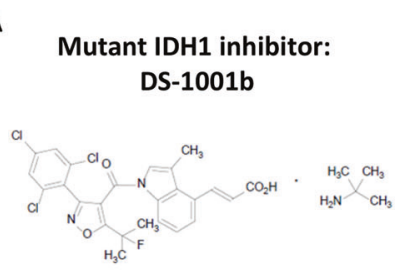

C

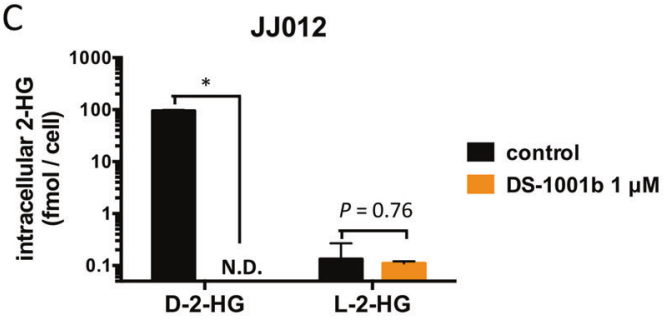

D

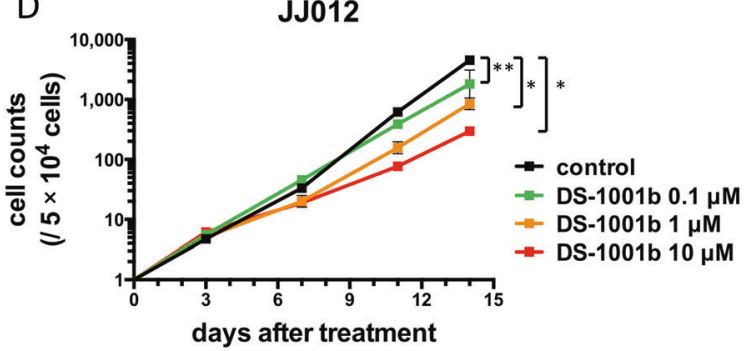

$\mathrm{E}$

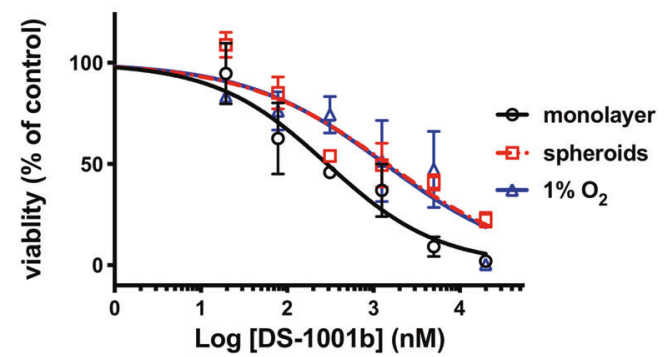

$\mathrm{F}$

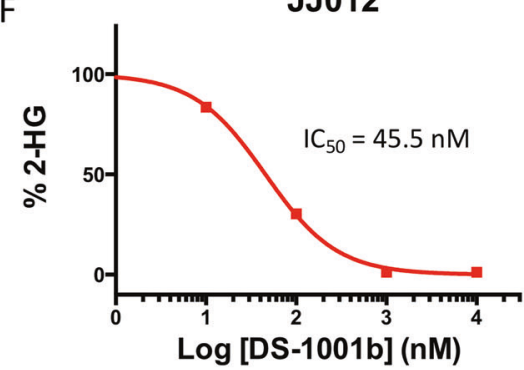

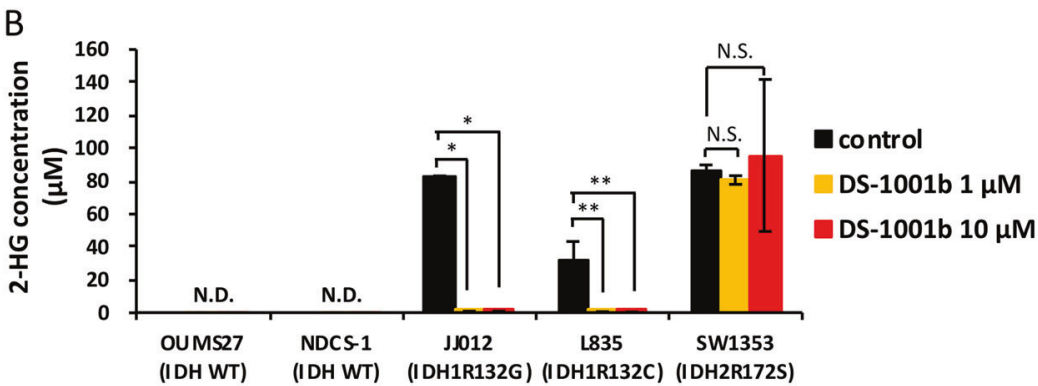

$\mathbf{8 3 5}$

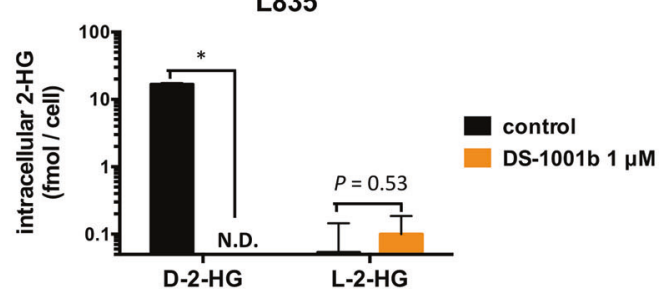

L835

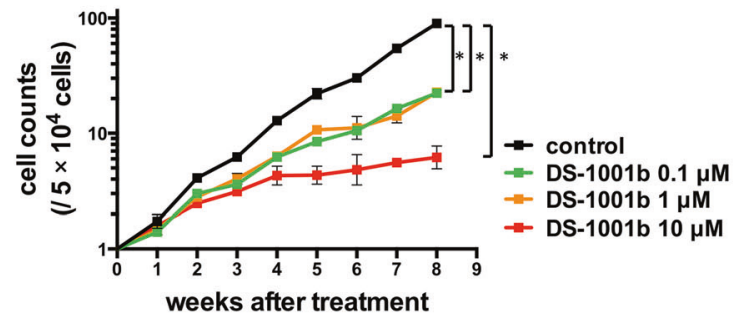

L835

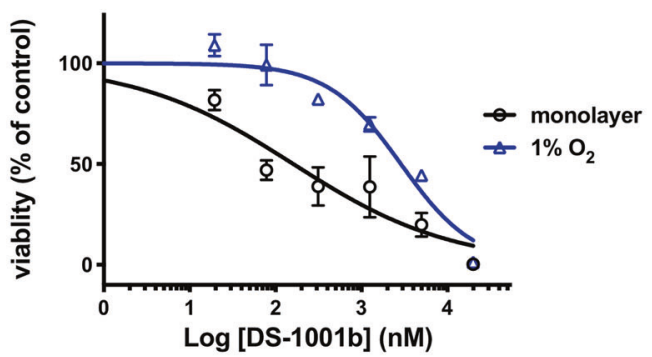

L835

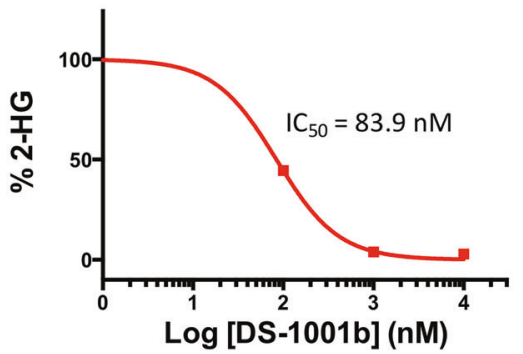

lines. The heterozygous IDH mutation was detected in JJ012 (IDHIR132G), L835 (IDHIR132C), and SW1353 (IDH2R172S) cells (Supplementary Fig. 1A), whereas OUMS27 and NDCS-1 cells had no mutation in either allele (data not shown). wild-type IDH1. The role of mutant IDH1 in chondrosarcoma was investigated by assessing the effects of DS$1001 \mathrm{~b}$ on chondrosarcoma cell lines with wild-type or mutant IDH. Sanger sequencing was performed to determine the presence of IDH mutations in the different cell 
Fig. 1 DS-1001b impairs the proliferation of IDH1 mutant chondrosarcoma cell lines and decreases 2-HG levels. a Chemical structure of DS-1001b. b Comparison of intracellular 2-HG levels in chondrosarcoma cell lines treated with 1 and $10 \mu \mathrm{M}$ DS-1001b for $72 \mathrm{~h}$. The chondrosarcoma cell lines OUMS27 (IDH WT), NDCS-1 (IDH WT), JJ012 (IDH1R132G), L835 (IDH1R132C), and SW1353 (IDH2R172S) were used. N.D., not detected. c Bar graphs show intracellular D-2-HG and L-2-HG levels in JJ012 and L835 cells treated with $1 \mu \mathrm{M}$ DS-1001b for $72 \mathrm{~h}$. N.D., not detected. d Cell proliferation of JJ012 and L835 cells treated with different concentrations of DS-1001b for the indicated times. The $Y$-axis shows the cumulative cell numbers. e Cell viability of JJ012 and L835 cells treated with different concentrations of DS-1001b. JJ012 cells were treated with DS-1001b for 7 days under normoxic (monolayer) and hypoxic $\left(1 \% \mathrm{O}_{2}\right)$ conditions, and in 3D cultures (spheroids). L835 cells were treated for 3 weeks under normoxic (monolayer) and hypoxic conditions $\left(1 \% \mathrm{O}_{2}\right)$. f Relative 2-HG levels in JJ012 and L835 cells treated with different concentrations of DS-1001b for $72 \mathrm{~h}$. The levels were normalized to vehicle treatment. All data represent the mean of triplicates \pm s.d. $* P<0.001,{ }^{*} * P<0.05$ (Student's $t$-test)

Measurement of intracellular 2-HG by LC-MS/MS showed that 2-HG levels were significantly higher in IDHmutated cell lines than in IDH wild-type cell lines, in which 2-HG was barely detectable (Fig. 1b). The levels of 2-HG did not differ significantly between mutant IDH1 and IDH2 cell lines. Exposure to $1 \mu \mathrm{M}$ DS-1001b for $72 \mathrm{~h}$ markedly decreased intracellular 2-HG levels in JJ012 and L835 cells, whereas DS-1001b had no effect in SW1353, OUMS27, and NDCS-1 cells. Intracellular D-2-HG levels measured by LC-TOFMS were 100-fold higher than L-2-HG levels and completely blocked with $1 \mu \mathrm{M}$ DS-1001b for $72 \mathrm{~h}$ in both IDH1-mutated cell lines (Fig. 1c).

The IDH1 mutant cell lines JJ012 and L835 were treated with different concentrations of DS-1001b $(0-10 \mu \mathrm{M})$, and cell proliferation was assessed by counting cumulative cell numbers. DS-1001b impaired proliferation in both cell lines in a dose-dependent manner (Fig. 1d), whereas the drug had little effect on the proliferation of the IDH wild-type cell lines OUMS27 and NDCS-1 (Supplementary Fig. 1B); GI ${ }_{50}$ values for JJ012, L835, OUMS27, and NDCS-1 cells were $81 \mathrm{nM}$ (day 14), $77 \mathrm{nM}$ (6 weeks), >10 $\mu \mathrm{M}$ (day 10), and $>10 \mu \mathrm{M}$ (day 10), respectively. Chondrosarcoma is generally resistant to chemotherapy because of its low vascularity and the hypoxic condition [2, 35]. Therefore, the effect of DS-1001b on cell viability was evaluated under 3D (spheroids) and hypoxic $\left(\begin{array}{lll}1 \% & \mathrm{O}_{2}\end{array}\right)$ conditions. JJ012 spheroids generated from $1.0 \times 10^{3}$ cells reached a diameter of $\sim 200 \mu \mathrm{m}$ after 3 days (Supplementary Fig. 1C), whereas L835 cells did not form spheroids because of the slow rate of cell growth. DS-1001b decreased cell viability in a dose-dependent manner even under 3D and hypoxic conditions, although cell viability was significantly higher in cells cultured as spheroids and under hypoxic conditions than in cells cultured in a monolayer (Fig. 1e); the $\mathrm{GI}_{50}$ values for JJ012 cells at 7 days after DS-1001b treatment were $289.6 \mathrm{nM}$ (monolayer), $1,444 \mathrm{nM}$ (spheroids), and $1,363 \mathrm{nM}\left(1 \% \mathrm{O}_{2}\right)$, and those for L835 cells at 3 weeks after DS-1001b treatment were $160.9 \mathrm{nM}$ (monolayer) and $2,878 \mathrm{nM}\left(1 \% \mathrm{O}_{2}\right)$. Treatment with DS-1001b decreased intracellular 2-HG levels in a dose-dependent manner in JJ012 and L835 cells (Fig. 1f). The production of intracellular 2-HG in JJ012 and L835 cells was completely blocked in response to treatment with $1 \mu \mathrm{M}$ DS-1001b for $72 \mathrm{~h}$, and this was consistent with the extent of inhibition of cell growth. Furthermore, DS-1001b treatment for $72 \mathrm{~h}$ did not clearly induce apoptosis (Supplementary Fig. 1D). These results demonstrate that DS-1001b selectively impairs cell proliferation in IDH1 mutant chondrosarcoma cells and concomitantly decreases intracellular 2-HG levels.

\section{Inhibition of mutant IDH1 promotes normal chondrocyte differentiation by upregulating SOX9 in $\mathbf{L} 835$ cells}

To investigate the molecular mechanism by which inhibition of mutant IDH1 regulates the proliferation of chondrosarcoma cells, we performed RNA sequencing in L835 cells. The analysis identified 4,783 genes showing $\geq 1$.2-fold upregulation and 5,028 genes showing $\leq 1$.2-fold downregulation in treated cells. Next, pathway analysis was used to identify the signaling pathways activated or inactivated upon inhibition of mutant IDH1. The transcriptional profiles of DS-1001b-treated L835 cells were characterized by the upregulation of genes related to the mesodermal differentiation pathway, the vitamin $\mathrm{D}$ receptor pathway, retinoic acid signaling, and the chondrocyte differentiation pathway (Fig. 2a). L835 is derived from a grade 3 conventional chondrosarcoma patient and shows a chondrogenic phenotype [36]. Furthermore, because previous reports demonstrated that inhibition of mutant IDH induces the differentiation of AML and glioma cells [26, 29, 33], we hypothesized that normal chondrocyte differentiation would also be induced by inhibition of mutant IDH1 in conventional chondrosarcoma. We therefore examined this pathway in further experiments.

The results of RT-PCR confirmed that DS-1001b treatment markedly upregulated SOX 9 and $R U N X 2$, which are upstream genes in the chondrocyte differentiation pathway, in a time-dependent manner (Fig. 2b). Western blot analysis showed that DS-1001b markedly upregulated SOX9, a key regulator of chondrocyte differentiation, at the protein level (Fig. 2c). Because L835 cells showed a slower growth rate than other cell lines, the upregulation of SOX9 and RUNX2 was mostly detected at 6 weeks after DS-1001b treatment. Assessment of the expression of downstream genes in the chondrocyte differentiation pathway, including COL2A1, COL1OA1, and ACAN, by RT-PCR showed that DS-1001b significantly upregulated the expression of these genes 
A

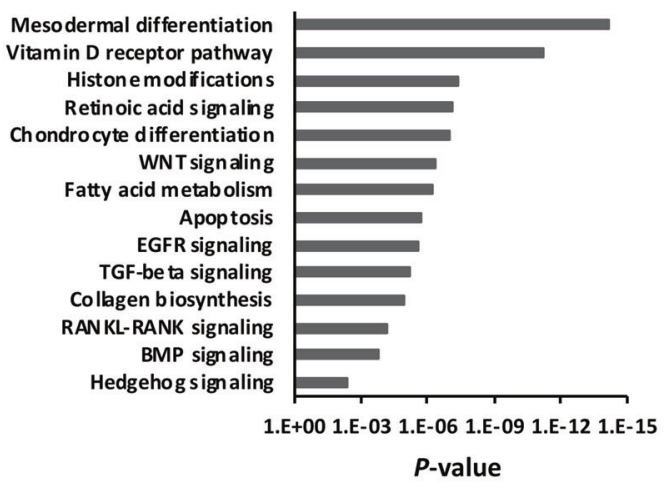

C

DS-1001b $(\mu \mathrm{M}) \quad 0 \quad 1 \quad 10$
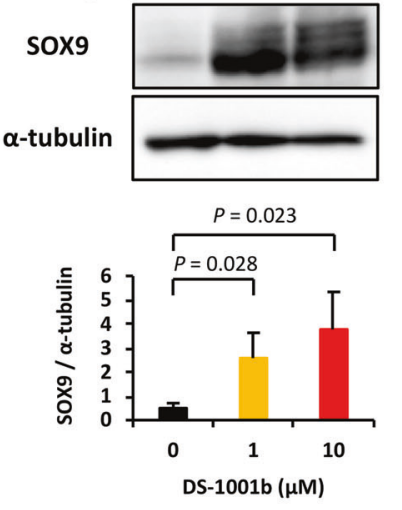

$E$

H\&E
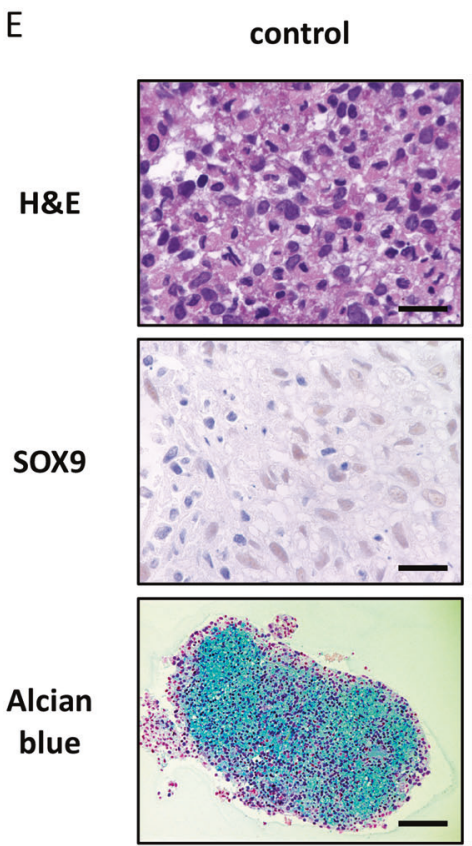

D
B

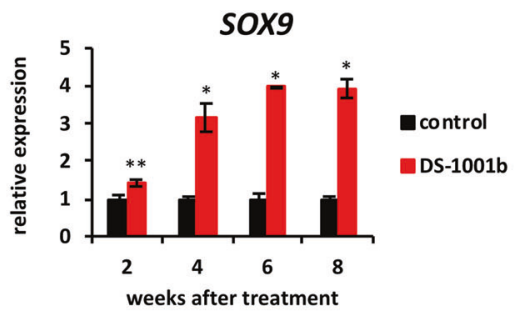

RUNX2

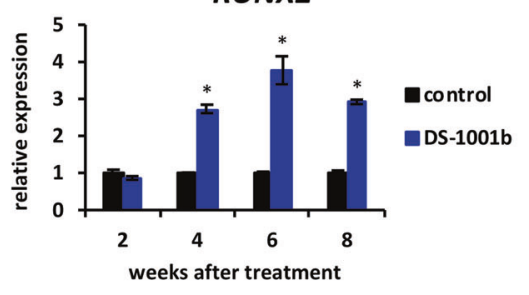

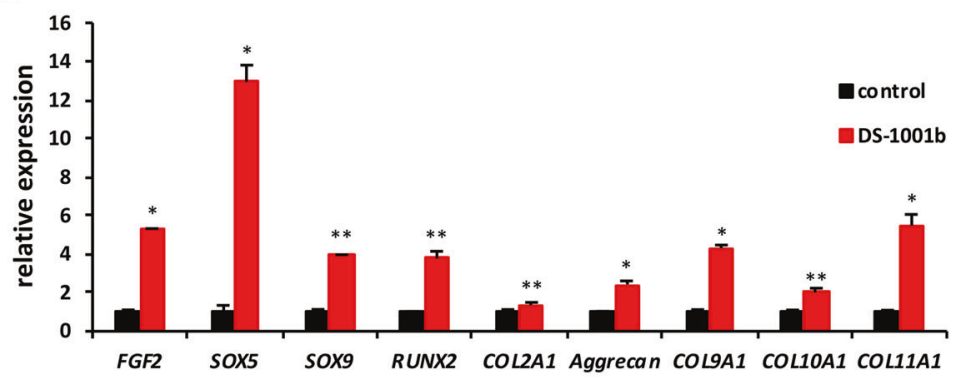

$\mathrm{F}$

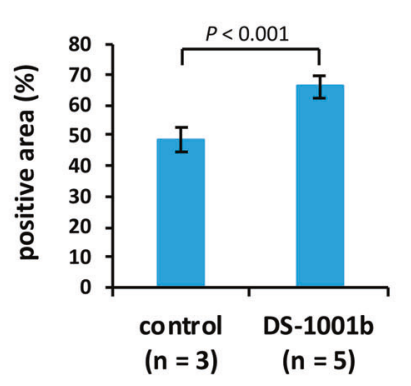

(Fig. 2d). When L835 cells were placed in a chondrogenic medium as 3D pellet cultures for 6 weeks, they synthesized a cartilaginous matrix resembling primary tumors (Fig. 2e) [36]. DS-1001b treatment for 2 weeks increased lacunar spaces and decreased nuclear size and hyperchromasia of L835 cells in H\&E staining. SOX9 was expressed at higher levels in the nucleus of DS-1001b-treated L835 cells than in untreated L835 cells (Fig. 2e). DS-1001b also significantly 
Fig. 2 Inhibition of mutant IDH1 upregulates chondrocyte differentiation pathway genes in L835 cells. a Upregulated genes identified by RNA-seq in L835 cells treated with DS-1001b at $10 \mu \mathrm{M}$ for 6 weeks. b qRT-PCR analysis of $S O X 9$ and $R U N X 2$ relative expression in L835 cells treated with DS-1001b at $10 \mu \mathrm{M}$. The $Y$-axis represents fold-change in gene expression after normalization to ACTB. c (Upper) Western blot analysis of SOX9 in L835 cells treated with DS-1001b $(0,1$, and $10 \mu \mathrm{M})$ for 6 weeks. $\alpha$-tubulin was used as a loading control. (Bottom) Bar graphs show the results of western blot quantification $(n=3)$. $\mathbf{d}$ qRT-PCR analysis of the relative expression of chondrocyte differentiation-related genes in L835 cells treated with DS-1001b at $10 \mu \mathrm{M}$ for 6 weeks. The $Y$-axis represents fold-change in gene expression after normalization to $A C T B$. e Representative images of (Upper) Hematoxylin\&Eosin (H\&E), (Middle) SOX9, and (Bottom) Alcian blue staining with or without DS-1001b treatment. 3D pellets of L835 cells were cultured in chondrogenic medium for 6 weeks. Five pellets were exposed to $100 \mathrm{nM}$ DS-1001b from 4 to 6 weeks $(n=3$ control group, $n=5$ DS-1001b group). Scale bar, $20 \mu \mathrm{m}$ (H\&E and SOX9), $100 \mu \mathrm{m}$ (Alcian blue). f Bar graphs show the percentage of Alcian blue positive areas after treatment with vehicle control or DS$1001 \mathrm{~b}$ at $100 \mathrm{nM}$ for 2 weeks. Error bars represent the mean \pm s.d. $* P$ $<0.001, * * P<0.005$ (Student's $t$-test)

increased Collagen II expression around SOX9 positive cells (Supplementary Fig. 2). Furthermore, Alcian blue staining for detection of matrix proteoglycan revealed that DS-1001b significantly increased the chondrocyte matrix area (Fig. 2e, f). These results suggested that inhibition of mutant IDH1 by DS-1001b impaired cell proliferation by promoting normal chondrocyte differentiation in conventional chondrosarcoma cells.

\section{Inhibition of mutant IDH induces cell cycle arrest by activating CDKN1C in JJ012 cells}

Unlike the response in L835 cells, inhibition of mutant IDH1 by DS-1001b treatment in JJ012 cells had no effect on the chondrocyte differentiation pathway (data not shown). JJ012 cells have a more dedifferentiated morphology [37], and therefore show few characteristics of cartilaginous tumors. Consistently, the expression of downstream genes in the chondrocyte differentiation pathway including COL2A1, COL10A1, and ACAN was barely detected by RTPCR in JJ012 cells (data not shown), suggesting that the mechanism of action of DS-1001b in dedifferentiated cells differs from that in conventional chondrosarcoma cells. Therefore, other pathways related to the inhibition of proliferation in dedifferentiated-like JJ012 cells were investigated by RNA sequencing. The results showed that the transcriptional profiles of DS-1001b-treated JJ012 cells were characterized by the upregulation of genes related to the cell cycle, apoptosis, WNT signaling, and Hedgehog signaling (Fig. 3a). Because DS-1001b markedly induced the expression of cell cycle-related genes and particularly those related to the G1/S transition, we next focused on this pathway. Analysis of cell cycle progression by flow cytometry showed that treatment with $1 \mu \mathrm{M}$ DS-1001b for 7 days induced G1 phase arrest. DS-1001b increased the percentage of cells in $\mathrm{G} 0 / \mathrm{G} 1$ phase by $5.4 \%(P<0.0005)$ and decreased that of cells in $\mathrm{S}$ phase by $4.4 \%(P<0.0001)$ (Fig. 3b). Of the genes in the cell cycle pathway, CDKNIC (P57) showed the highest upregulation in response to DS$1001 \mathrm{~b}$ treatment (Fig. 3c). RT-PCR confirmed that DS$1001 \mathrm{~b}$ treatment significantly upregulated CDKNIC (Fig. $3 \mathrm{~d}$ ), and western blot analysis showed the upregulation of CDKN1C by DS-1001b at the protein level (Fig. 3e).

To examine the effects of CDKN1C activation on IDH1 mutant chondrosarcoma cells, we generated CDKN1Coverexpressing JJ012 cells. CDKN1C overexpression, which did not induce apoptosis (Supplementary Fig. 3), significantly impaired cell proliferation compared with that of control cells (Fig. 4a). To determine whether the DS$1001 \mathrm{~b}$-induced activation of CDKN1C was responsible for the proliferation impairment in JJ012 cells, CDKN1C was knocked out using the CRISPR/Cas9 system in vitro. The downregulation of CDKN1C was confirmed by western blotting (Fig. 4b). In vitro cell proliferation assays showed that CDKN1C knockout rescued the growth inhibition of JJ012 cells induced by DS-1001b (Fig. 4c). These results suggest that repression of CDKN1C mediated by mutation of IDH is important for tumor progression in JJ012 cells, and overactivation of CDKN1C induced by DS-1001b impairs the proliferation of JJ012 cells, which have a dedifferentiated-like phenotype.

\section{Inhibition of mutant IDH1 upregulates SOX9 and CDKN1C by decreasing H3K9me3 levels}

2-HG induces aberrant epigenetic changes by inhibiting histone lysine demethylases and DNA demethylases. We therefore examined the global trimethylation of histone $\mathrm{H} 3 \mathrm{~K} 4, \mathrm{H} 3 \mathrm{~K}$, and H3K27 in mutant IDH1 and wild-type IDH cell lines. Western blot analysis showed a significant increase of both active (H3K4me3) and repressive (H3K9me3 and H3K27me3) marks in mutant IDH1 cells (Fig. 5a, Supplementary Fig. 4A). DS-1001b-mediated inhibition of mutant IDH1 significantly reduced the levels of H3K4me3 and H3K9me3 in JJ012 and L835 cells, whereas H3K27me3 levels remained unchanged in both cell lines (Fig. 5b, Supplementary Fig. 4B). By contrast, DS1001b had little effect on the levels of these histone marks in NDCS-1 cells (Supplementary Fig. 4C). These results suggest that mutant IDH1 induces aberrant histone methylation, and inhibition of mutant IDH1 contributes to restoring $\mathrm{H} 3 \mathrm{~K} 4 \mathrm{me} 3$ and $\mathrm{H} 3 \mathrm{~K} 9 \mathrm{me} 3$ to normal levels in chondrosarcoma cells.

To explore whether direct crosstalk between mutant IDH and SOX9 was involved in the effect of the IDH mutation, chromatin immunoprecipitation (ChIP)-qPCR was 
A

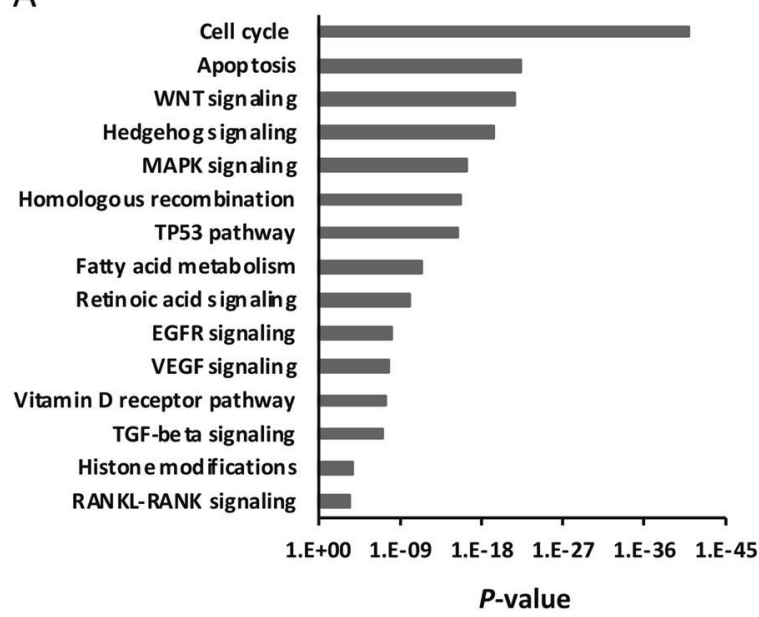

C

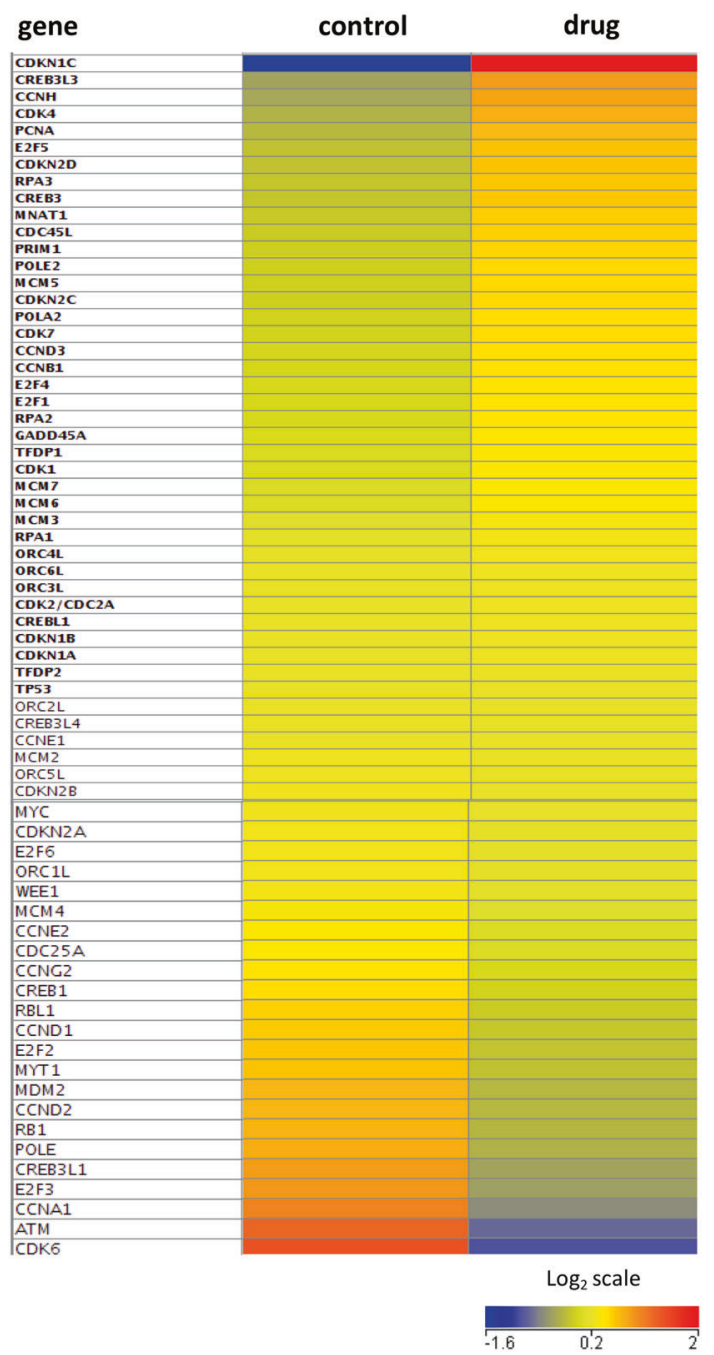

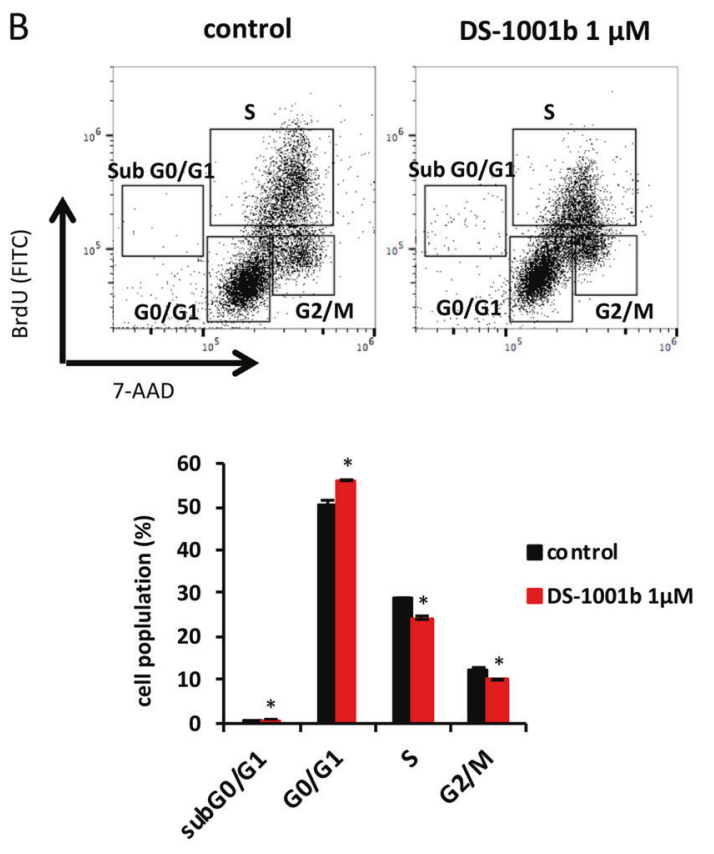

D
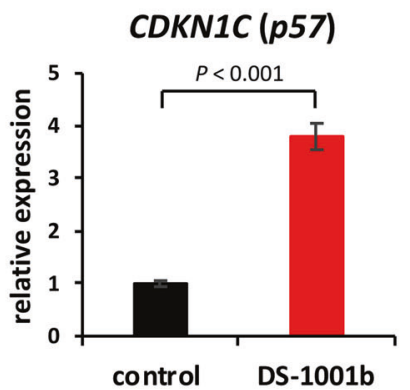

$E$
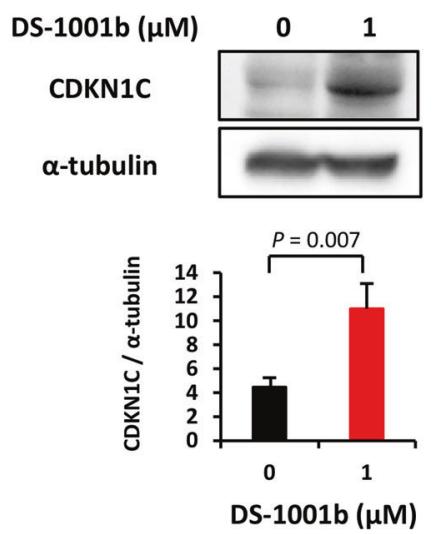

performed using antibodies specific for H3K4me3, H3K9me3, and H3K27me3 in L835 cells. The results showed that the SOX9 locus in L835 cells was marked by both the active (H3K4me3) and repressive (H3K9me3 and H3K27me3) marks, and DS-1001b treatment for 7 days markedly reduced the levels of $\mathrm{H} 3 \mathrm{~K} 9 \mathrm{me} 3$ at the locus, with 
Fig. 3 Inhibition of mutant IDH1 upregulates CDKN1C in JJ012 cells. a Upregulated genes identified by RNA-seq in JJ012 cells treated with DS-1001b at $1 \mu \mathrm{M}$ for 7 days. b Analysis of cell cycle progression using BrdU and 7-AAD in JJ012 cells. (Top) Representative FACS plots of cells in each cell cycle phase after treatment with vehicle control or DS-1001b at $1 \mu \mathrm{M}$ for 7 days. (Bottom) Bar graphs show the cell populations in each cell cycle phase after treatment with DS-1001b $(0$ and $1 \mu \mathrm{M})$ for 7 days. Error bars represent the mean \pm s.d. $* P<$ 0.001 (Student's $t$-test). c Heatmap of G1/S transition pathway-related gene expression in JJ012 cells treated with or without $1 \mu \mathrm{M} \mathrm{DS}-1001 \mathrm{~b}$ for 7 days ( $\log _{2}$ scale). Expression levels were normalized in two replicates of each sample. d qRT-PCR analysis of CDKN1C relative expression in JJ012 cells treated with DS-1001b at $1 \mu \mathrm{M}$ for 7 days. The $Y$-axis represents fold-change in gene expression after normalization to $A C T B$. e (Upper) Western blot analysis of CDKN1C in JJ012 cells treated with DS-1001b at $1 \mu \mathrm{M}$ for 7 days. $\alpha$-tubulin was used as a loading control. (Bottom) Bar graphs show the results of western blot quantification $(n=3)$

little effect on the levels of H3K4me3 and H3K27me3 (Fig. $5 \mathrm{c})$. These results demonstrate that SOX9 is directly regulated by mutant IDH1 in L835 cells, and DS-1001b upregulates SOX9 expression by decreasing H3K9me3 levels, thus promoting normal chondrocyte differentiation. ChIPqPCR analysis also demonstrated that inhibition of mutant IDH1 by DS-1001b markedly decreased H3K9me3 levels at the CDKNIC locus in JJ012 cells (Fig. 5d), resulting in cell cycle arrest through the upregulation of CDKN1C. Although DS-1001b impaired cell proliferation in the two cell lines via different mechanisms related to the different characteristics of the cells, the results suggested a common mechanism underlying the effects of mutant IDH1 inhibition in the two cell lines by which 2-HG-induced aberrant H3K9 trimethylation of target genes is restored, leading to the upregulation of SOX9 and CDKN1C.

\section{Continuous administration of DS-1001b impairs tumor growth in xenograft mice}

The effect of DS-1001b on mutant IDH1 cell lines was examined in vivo in a xenograft tumor model. Mice harboring JJ012 subcutaneous tumors were treated with control diet or DS-1001b at 3-9 weeks after transplantation (Fig. 6a). Continuous administration of DS-1001b significantly impaired subcutaneous tumor growth in JJ012 xenograft mice (Fig. 6b, c and Supplementary Fig. 5A), and tumor weight was also markedly decreased in treated mice at the final follow-up evaluation (Supplementary Fig. 5B). Measurement of intratumoral 2-HG levels after completion of the treatment showed that 2-HG levels were markedly lower in DS-1001b-treated mice than in untreated mice $(P<$ 0.001) (Fig. 6d). In addition, DS-1001b suppressed the increase of plasma 2-HG levels in this model, whereas the levels gradually increased in untreated mice $(P=0.006)$ (Fig. 6e). The plasma concentration of DS-1001b in mice was $2.4-10.4 \mu \mathrm{M}$, which did not cause body weight loss or other serious side effects (Supplementary Fig. 5C). RT-PCR confirmed that DS-1001b treatment significantly upregulated $C D K N 1 C$ in xenograft tumors, consistent with the in vitro results (Fig. 6f). JJ012 tumors had a more dedifferentiated morphology in $\mathrm{H} \& \mathrm{E}$ staining (Fig. 6g), as reported previously [37]. Furthermore, immunohistochemical analysis of CDKN1C showed that it was positively expressed in the nucleus of some DS-1001b-treated JJ012 cells compared with untreated JJ012 cells (Fig. 6g). These results indicate that mutant IDH1-targeted therapy with DS$1001 \mathrm{~b}$ is effective in a xenograft model in vivo.

\section{Discussion}

In the present study, the novel, orally bioavailable, selective mutant IDH1 inhibitor DS-1001b was used to elucidate the role of IDH mutations in the development and maintenance of chondrosarcoma cells. Tumor progression involved SOX9 and CDKN1C repression in different chondrosarcoma cell lines. Furthermore, DS-1001b reduced the levels of $\mathrm{H} 3 \mathrm{~K} 4 \mathrm{me} 3$ and $\mathrm{H} 3 \mathrm{~K} 9 \mathrm{me} 3$, restoring the aberrant histone modification induced by 2 -HG.

Novel drugs were recently developed for the treatment of soft tissue sarcomas, and some of them have shown promise for clinical application. Pazopanib [38], trabectedin [39], and eribulin mesylate [40] significantly prolonged the progression-free survival of patients in clinical trials and are used for the treatment of patients with advanced pretreated soft tissue sarcomas. Olaratumab [41], New York esophageal squamous cell carcinoma 1 [42, 43], and antiprogrammed death 1 antibody $[44,45]$ are currently being tested as targeted therapies in clinical trials for the treatment of various soft tissue sarcomas. However, few drugs against bone sarcomas have been developed in the past decades. Although cytotoxic chemotherapy combined with surgery and radiotherapy plays a key role in the treatment of bone sarcomas, there are few treatment options for relapsed and metastatic cases. This is particularly limiting in chondrosarcomas, which are highly resistant to both chemotherapy and radiotherapy [2]. In conventional chondrosarcoma, drug resistance is related to the low vascularity and abundant extracellular matrix of these tumors, which prevent drugs from reaching and acting on malignant chondrocytes. Dedifferentiated chondrosarcoma, which shows an abrupt transition from cartilage to more aggressive components, progresses rapidly and is associated with a poor prognosis despite wide resection or chemotherapy $[2,5]$. Therefore, the development of novel-targeted therapies for the treatment of relapsed or dedifferentiated chondrosarcoma is eagerly awaited.

IDH mutations in chondrosarcoma are considered a potential therapeutic target for inoperable and metastatic 


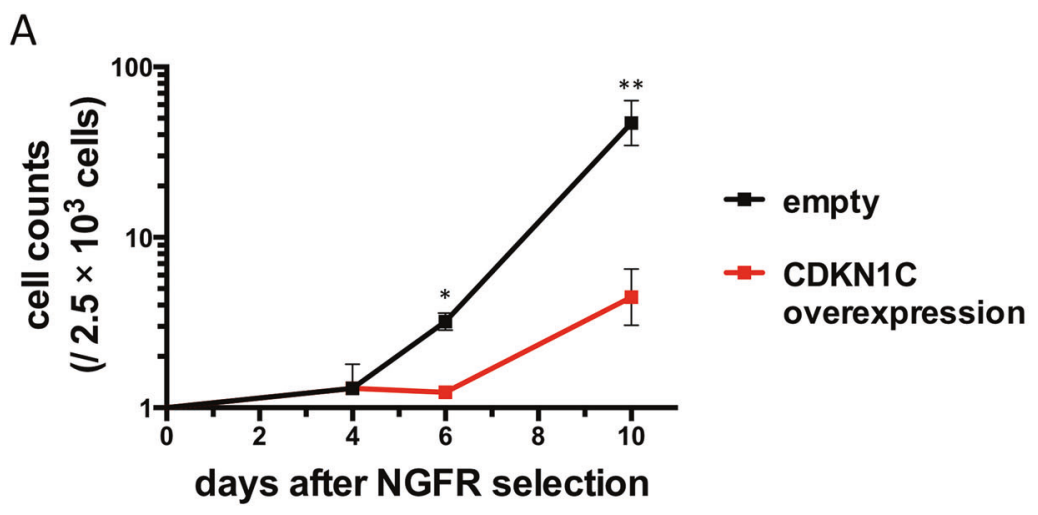

B

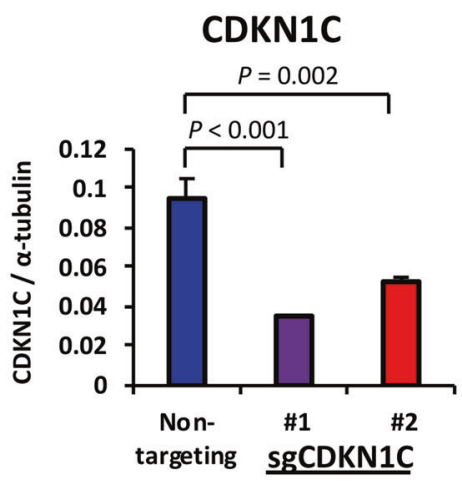

C

Non-targeting

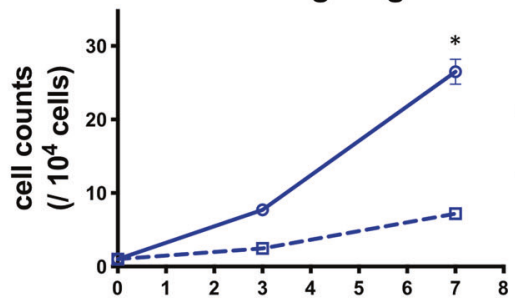

Non-targeting

control

$\rightarrow$ - Non-targeting

DS-1001b $1 \mu \mathrm{M}$

days after treatment

sg CDKN1C \#1

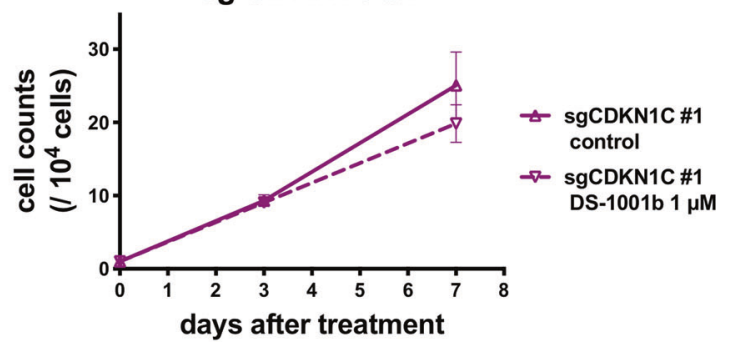

Fig. 4 The repression of CDKN1C mediated by mutant IDH1 is important for tumor progression. a Cell proliferation of CDKN1Coverexpressing JJ012 cells at the indicated times. The $Y$-axis shows the relative cumulative cell numbers. b (Left) Western blot analysis of CDKN1C in Cas9-expressing JJ012 cells electroporated with nontargeting crRNA or crRNA targeting CDKN1C and tracrRNA (\#1 and \#2). $\alpha$-tubulin was used as a loading control. (Right) Bar graphs show

cases because they are gain-of-function mutations and are present in $\sim 50 \%$ of chondrosarcoma patients $[12,14,15]$. Most mutant IDH chondrosarcoma patients harbor IDH1

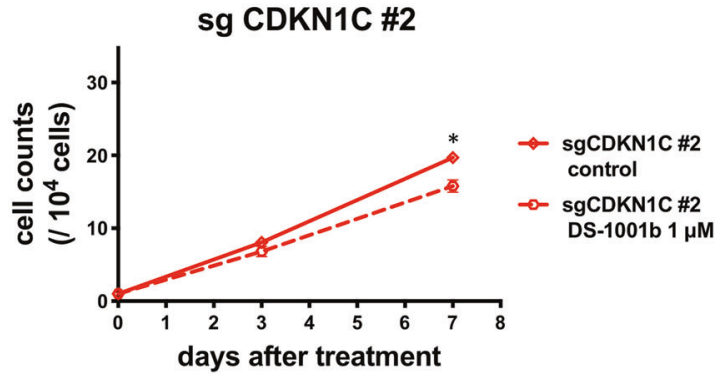

the results of western blot quantification $(n=3)$. $\mathbf{c}$ Cell proliferation of CDKN1C-knockout JJ012 cells treated with $1 \mu \mathrm{M}$ DS-1001b for 7 days. Approximately $10^{4}$ cells were plated on a $6 \mathrm{~cm}$ dish and the cell number was set as day 0 . The $Y$-axis shows the cumulative cell numbers. Data are expressed as the mean of triplicates $( \pm$ s.d.). $* P<$ $0.005, * * P<0.05$ (Student's $t$-test)

mutations, which is similar to glioma and cholangiocarcinoma, which are characterized by the frequency of IDH mutations $[9,10]$. The development of mutant IDH1 
A

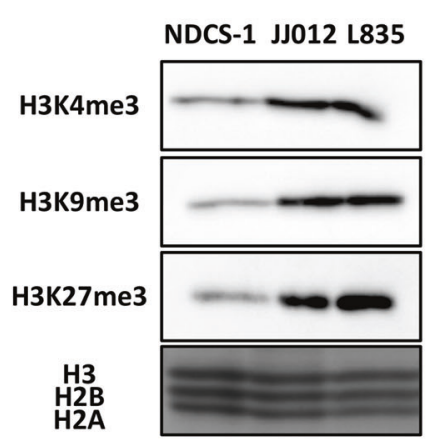

B

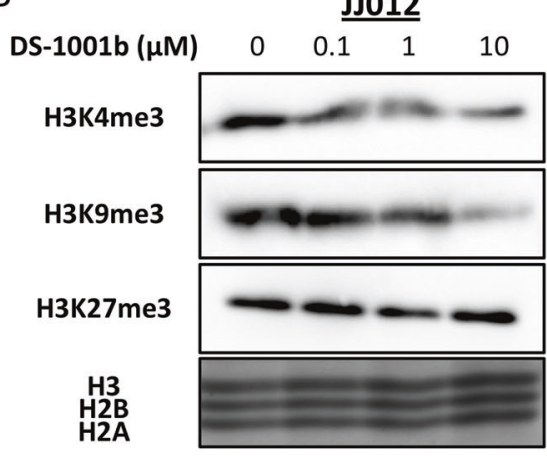

$\underline{\mathbf{L 8 3 5}}$

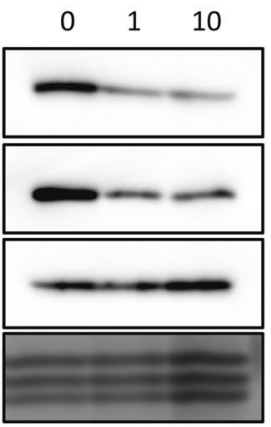

C

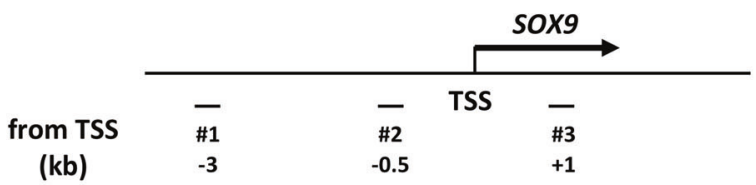

H3K4me3

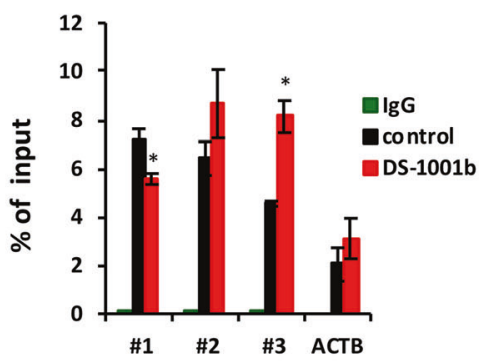

H3K9me3

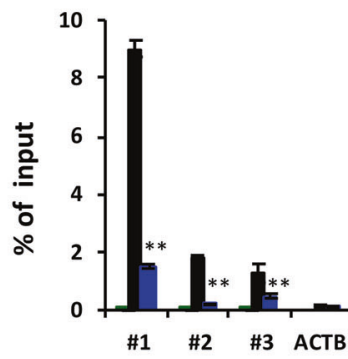

H3K27me3

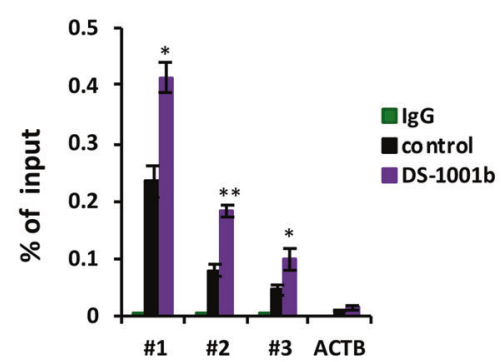

D

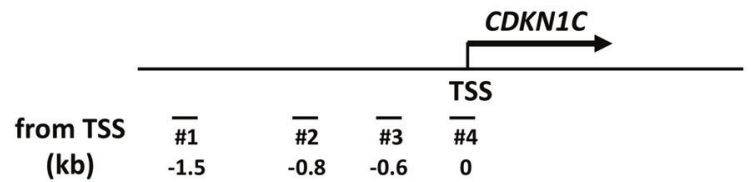

H3K4me3

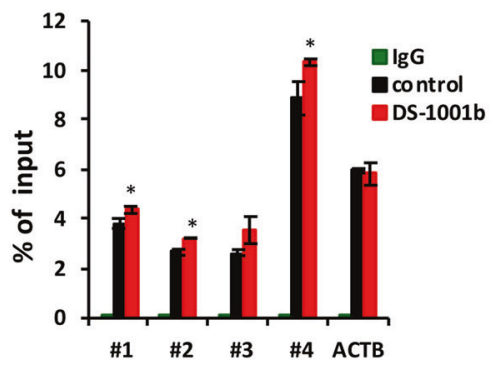

H3K9me3

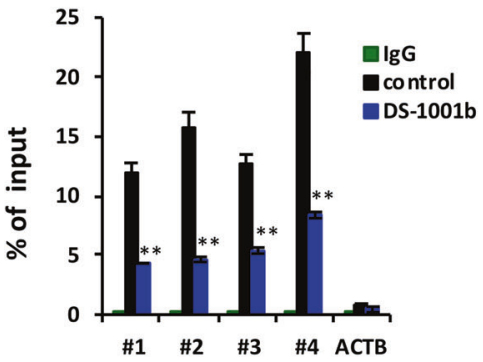

H3K27me3

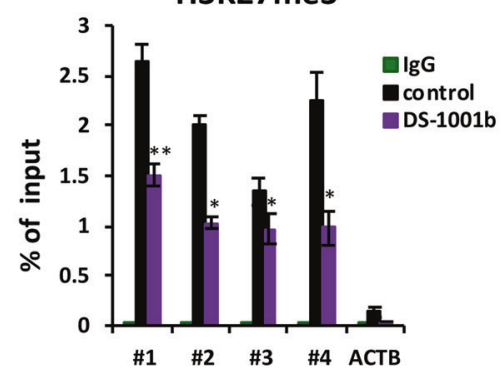

Fig. 5 Inhibition of mutant IDH1 upregulates SOX9 and CDKN1C by decreasing $\mathrm{H} 3 \mathrm{~K} 9 \mathrm{me} 3$ levels. a Western blot analysis of $\mathrm{H} 3 \mathrm{~K} 4 \mathrm{me} 3$, H3K9me3, and H3K27me3 in NDCS-1, JJ012, and L835 cells. Total H3 was used as a loading control. b Western blot analysis of $\mathrm{H} 3 \mathrm{~K} 4 \mathrm{me} 3, \mathrm{H} 3 \mathrm{~K} 9 \mathrm{me} 3$, and H3K27me3 in JJ012 and L835 cells treated with different concentrations of DS-1001b for 7 days. Total H3 was used as a loading control. c ChIP-qPCR of H3K4me3, H3K9me3, and H3K27me3 at the locus of the SOX9 gene in L835 cells treated with DS-1001b at $1 \mu \mathrm{M}$ for 7 days. The primers were designed around the transcriptional start site (TSS). Background signals were detected by
ChIP using rabbit IgG (green) for each sample. The $A C T B$ locus was used as the positive control for $\mathrm{H} 3 \mathrm{~K} 4 \mathrm{me} 3$ and negative control for H3K9me3 and H3K27me3. d ChIP-qPCR of H3K4me3, H3K9me3, and $\mathrm{H} 3 \mathrm{~K} 27 \mathrm{me} 3$ at the locus of the CDKN1C gene in JJ012 cells treated with DS-1001b at $1 \mu \mathrm{M}$ for 7 days. The primers were designed around the TSS. Background signals were detected by ChIP using rabbit $\operatorname{IgG}$ (green) for each sample. The $A C T B$ locus was used as the positive control for $\mathrm{H} 3 \mathrm{~K} 4 \mathrm{me} 3$ and negative control for $\mathrm{H} 3 \mathrm{~K} 9 \mathrm{me} 3$ and H3K27me3. Error bars represent the mean \pm s.d. $* P<0.05$, $* * P<$ 0.001 (Student's $t$-test) 
A
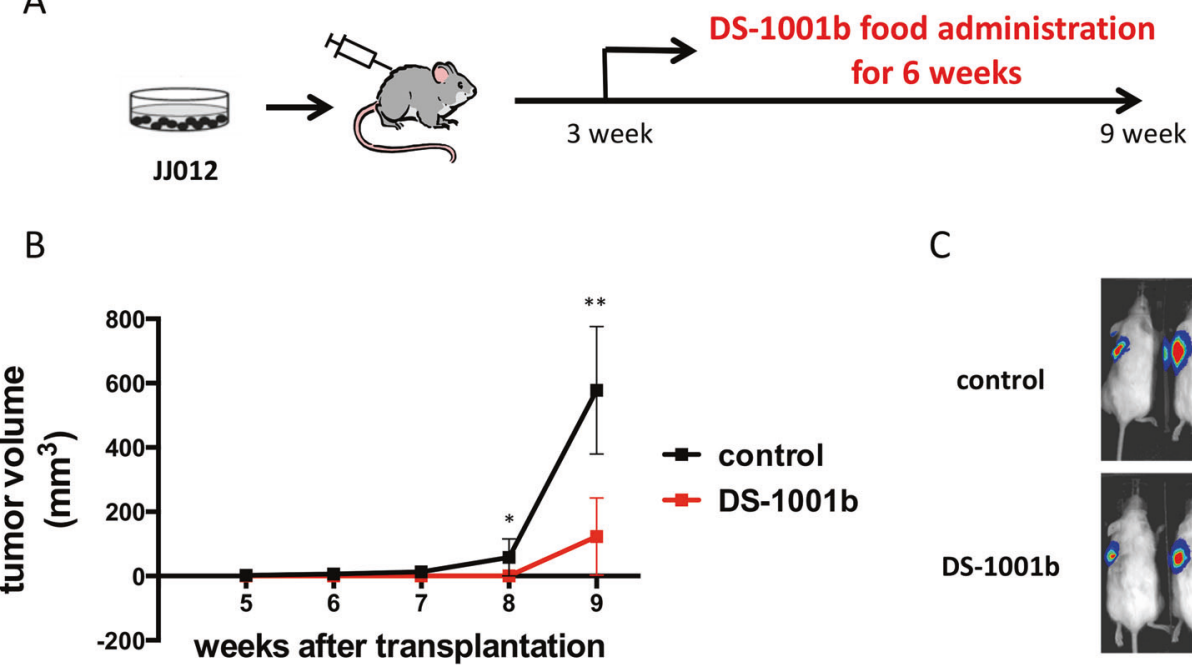

C

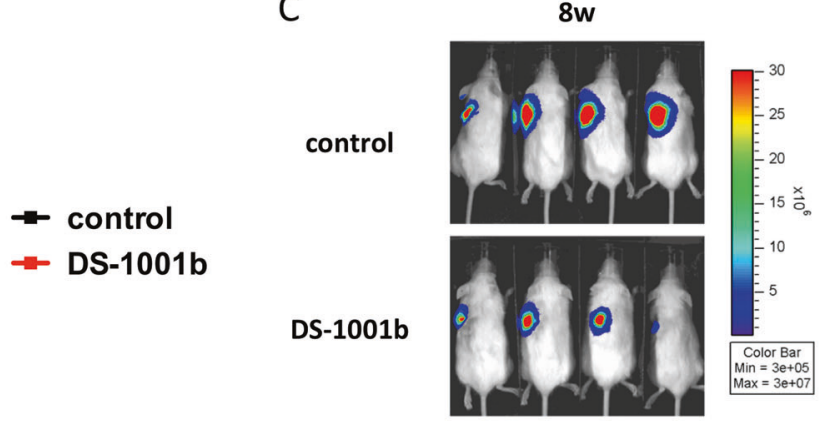

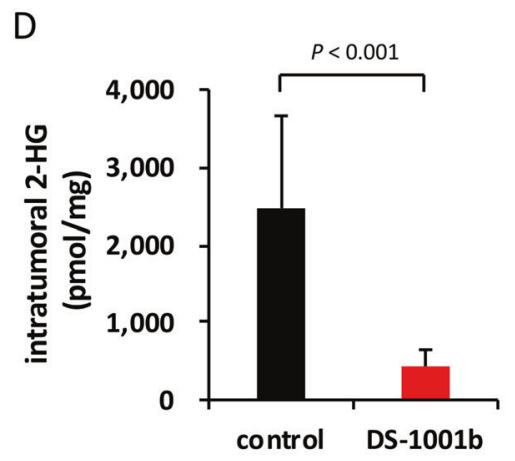

$\mathrm{F}$

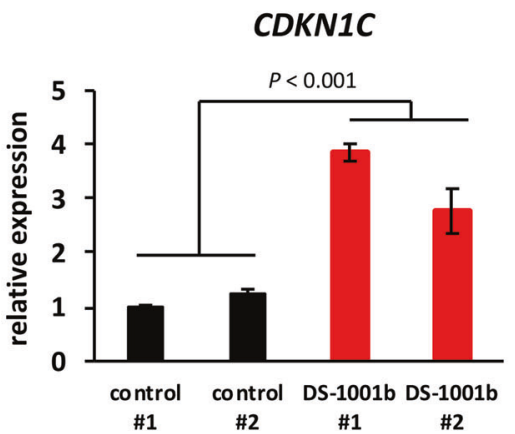

Fig. 6 DS-1001b has antineoplastic activity in JJ012 xenografts. a Experimental schematic of the in vivo study. NOD-SCID mice were transplanted subcutaneously with JJ012-Luc+ cells, and DS-1001b mixed with sterilized pellet food was fed continuously starting at 3 weeks after transplantation after confirmation of tumor engraftment by bioluminescence imaging ( $n=7$ mice in the DS-1001b group, $n=$ 5 mice in the control group). b Tumor volume in mice subcutaneously transplanted with JJ012-Luc+ cells. $\mathbf{c}$ Representative bioluminescence images showing the tumor burden of JJ012 xenografts at 8 weeks after transplantation in mice treated with DS-1001b or control diet. d Bar
$\mathrm{E}$

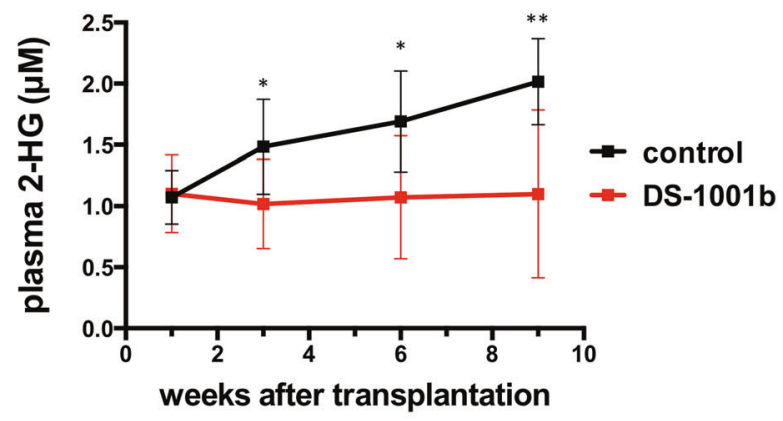

G

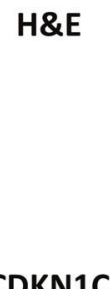

\section{control DS-1001b}

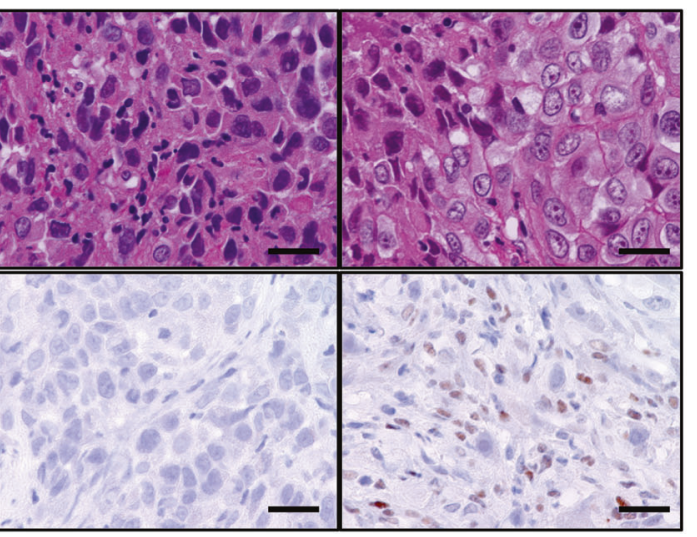

graphs show the levels of intratumoral 2-HG in subcutaneous tumors at the final follow-up in mice treated with control or DS-1001b. e Line graph representing the levels of plasma $2-\mathrm{HG}$, as measured every 2 or 3 weeks in mice treated with control or DS-1001b. f qRT-PCR showing the relative expression of CDKNIC in JJ012 subcutaneous tumors ( $n=2$ mice per group). The $Y$-axis represents fold-change in gene expression after normalization to $А C T B$. Error bars represent the mean \pm s.d. $* P<0.05$, ${ }^{*} P<0.001$ (Student's $t$-test). g Representative images of (Upper) H\&E and (Bottom) CDKN1C staining with or without DS-1001b treatment ( $n=3$ mice per group). Scale bar, $20 \mu \mathrm{m}$ 
inhibitors is therefore more urgent than that of mutant IDH2 inhibitors for the treatment of rare tumors such as chondrosarcoma and glioma.

In the present study, inhibition of mutant IDH1 by DS$1001 \mathrm{~b}$ significantly impaired the proliferation of two mutant IDH1 chondrosarcoma cell lines in a dose-dependent manner in vitro and in vivo. DS-1001b was also effective in these cells under 3D and hypoxic conditions, which resembled the intratumoral environment. Intracellular 2-HG levels were also markedly reduced by DS- $1001 \mathrm{~b}$ concomitant with the inhibition of cell proliferation. DS-1001b had no effect on the proliferation of wild-type IDH cells or the levels of intracellular 2-HG in mutant IDH2 cells, suggesting that this drug potently and selectively inhibits chondrosarcoma cells with mutations in IDH1. Treatment of mice bearing JJ012 xenograft tumors with DS-1001b markedly reduced intratumoral and serum 2-HG levels. 2$\mathrm{HG}$, which is regarded as an oncometabolite, is not produced in normal tissues; therefore, inhibition of mutant IDH1 by DS-1001b can maximize the effects of treatment and minimize adverse effects unlike cytotoxic chemotherapy. In the present model, continuous administration of DS1001b for 6 weeks did not cause significant side effects, suggesting that long-term continuous administration is clinically feasible. In addition, our results suggested that 2HG is a surrogate biomarker of treatment outcome in IDH mutant tumors, as 2-HG levels decreased markedly in response to DS-1001b treatment in parallel with the inhibition of mutant IDH chondrosarcoma cell proliferation. Therefore, the present study provided proof of concept for the inhibition of mutant IDH as a novel therapeutic approach and identified a useful biomarker, 2-HG, in unresectable, metastatic, and dedifferentiated chondrosarcoma.

The present results demonstrated that direct crosstalk between mutant IDH1 and SOX9, a key regulator of chondrocyte differentiation, occurs in L835 cells. In addition, DS-1001b-mediated removal of $\mathrm{H} 3 \mathrm{~K} 9 \mathrm{me} 3$ marks at the SOX9 locus upregulated the expression of SOX9. DS$1001 \mathrm{~b}$ also upregulated the expression of downstream genes in the chondrocyte differentiation pathway, and significantly increased the production of cartilaginous matrix in 3D cultures. These results indicate that DS-1001b promotes normal chondrocyte differentiation, thereby impairing the proliferation of L835 cells. Although these findings could not be confirmed in vivo because L835 cells are slow growing and do not form subcutaneous tumors, the present results are consistent with previous findings that mutant IDH inhibitors induce cell differentiation in AML and glioma cells with IDH mutations [29-31, 33]. Furthermore, long-term assays of L835 cells showed a significant growth delay, as inhibition of cell proliferation by DS-1001b was observed starting at 1 week after treatment. This can be attributed not only to the relatively slow cell cycle of L835 cells, but also the effects of mutant IDH inhibition on histone methylation status. Indeed, SOX9 was gradually upregulated in response to DS-1001b treatment, which reversed aberrant histone modification in 1 week. These results indicate that changes in the epigenetic status induced by mutant IDH1 inhibition gradually upregulate target genes, leading to chondrocyte differentiation in conventional chondrosarcoma cells.

However, DS-1001b did not induce chondrocyte differentiation in JJ012 cells and caused cycle arrest at the G1/S phase instead, inhibiting the growth of $\mathrm{JJ} 012$ cells. CDKN1C, which showed the greatest upregulation in response to DS-1001b among cell cycle-related genes, was one of the target genes regulating the proliferation of JJ012 cells in overexpression and knockout assays. Furthermore, repression of $\mathrm{H} 3 \mathrm{~K} 9 \mathrm{me} 3$ at the CDKNIC locus by DS$1001 \mathrm{~b}$ upregulated CDKN1C expression similar to the SOX9 locus in L835 cells.

We speculate that the different mechanisms of action of DS-1001b in the two cell lines reflect the different degrees of chondrocyte differentiation in these cell lines. L835 is a slow-growing cell line that resembles the primary conventional central chondrosarcoma producing myxoid matrix $[27,36]$. Our results suggest that normal chondrocyte differentiation is insufficient but induced to some extent in L835 cells, and that inhibition of mutant IDH1 by DS$1001 \mathrm{~b}$ promotes normal chondrocyte differentiation in conventional chondrosarcoma cells. On the other hand, despite being derived from intermediate-grade conventional chondrosarcoma [46], the JJ012 cell line shows high pleomorphism and nuclear atypia with prominent nucleoli [37], and its proliferation rate is higher than that of L835 cells. These dedifferentiated-like characteristics of JJ012 cells may be associated with the inability of DS-1001b to induce chondrocyte differentiation. The expression of downstream genes in the chondrocyte differentiation pathway, including COL2A1, COL1OA1, and ACAN, was barely detectable in JJ012 cells, as determined by RT-PCR, suggesting that the undifferentiated state of JJ012 cells is beyond the point of no return from which DS-1001b can induce chondrocyte differentiation. However, the present results indicate a common mechanism underlying the effect of mutant IDH1 in conventional and dedifferentiated-like chondrosarcoma. Namely, DS-1001b treatment reduced the levels of $\mathrm{H} 3 \mathrm{~K} 4 \mathrm{me} 3$ and $\mathrm{H} 3 \mathrm{~K} 9 \mathrm{me} 3$ in both conventional and dedifferentiated-like cell lines, suggesting that aberrant histone modifications caused by inhibition of histone demethylases by 2-HG lead to malignant progression from benign cartilaginous tumors. 2-HG reportedly inhibits the activity of histone demethylase. We therefore speculate that the function of KDM4, a demethylase that targets histone H3, may be impaired by 2-HG and restored by DS-1001b 
[21]. Further investigation of the role of mutant IDH in the initiation and progression of chondrosarcoma is needed for future clinical trials.

In summary, the present results strongly suggest that inhibition of mutant IDH1 with DS-1001b is a promising therapeutic approach for the treatment of chondrosarcoma. A phase I trial of DS-1001b involving glioma patients is underway (ClinicalTrials.gov identifier: NCT03030066), and this drug may lead to significant advances in the treatment of advanced and dedifferentiated chondrosarcoma.

\section{Materials and methods}

\section{Compounds}

The synthesis and characterization of DS-1001b (Daiichi Sankyo, Tokyo, Japan) are described in a Patent Cooperation Treaty application (publication number: WO2016052697 A).

\section{Cell lines and culture}

The chondrosarcoma cell lines JJ012 (IDHIR132G), L835 (IDH1R132C), SW1353 (IDH2R172S), OUMS27 (IDH WT), and NDCS-1 (IDH WT) were used in this study. JJ012, L835, and NDCS-1 were kindly provided by Dr. Joel A. Block (Rush Medical College, Chicago, IL, USA) [46], Dr. Judith V.M.G. Bovée (Leiden University, Leiden, The Netherlands) [36], and Dr. A. Ogose (Niigata University, Niigata, Japan) [47], respectively. SW1353 and OUMS27 cells were obtained from the American Type Culture Collection (ATCC; Manassas, VA, USA) and the Japan Health Science Research Resources Bank (Osaka, Japan), respectively. SW1353 was confirmed with STR DNA fingerprinting, which was performed by ATCC. Other cell lines were not registered in the database. Cells were maintained in RPMI1640 (Nacalai Tesque) supplemented with 10\% fetal bovine serum and $1 \%$ penicillin/streptomycin $(\mathrm{P} / \mathrm{S})$. Cells were grown at $37^{\circ} \mathrm{C}$ in a humidified incubator with 95\% air and 5\% $\mathrm{CO}_{2}$. All cell lines were tested for mycoplasma with the e-Myco plus Mycoplasma PCR detection kit (iNtRON Biotechnology) and found to be free from contamination.

\section{Statistical analyses}

Statistical significance was determined using the Student's $t$-test or analysis of variance after testing for normal distribution of data using GraphPad Prism 6 (GraphPad Software). Data were expressed as mean values, with error bars representing the standard deviation (s.d.).
Acknowledgements We wish to thank Dr Joel A. Block, Dr Judith V.M. G. Bovée, and Dr A. Ogose for providing important cell lines. We thank Yutaka Shima, Yuki Kagiyama, and Emi Takamatsu-Ichihara for expert advice and technical support. This work was supported by a Grant from Foundation for Promotion of Cancer Research (FPCR) (F.N.). IK was funded by Acceleration Transformative Research for Medical Innovation from the Japan Agency for Medical Research and Development and by the National Cancer Center Research and Development Fund.

\section{Compliance with ethical standards}

Conflict of interest HM and TS are employees of Daiichi Sankyo, Co., Ltd. The other authors declare that they have no conflict of interest.

Publisher's note: Springer Nature remains neutral with regard to jurisdictional claims in published maps and institutional affiliations.

Open Access This article is licensed under a Creative Commons Attribution 4.0 International License, which permits use, sharing, adaptation, distribution and reproduction in any medium or format, as long as you give appropriate credit to the original author(s) and the source, provide a link to the Creative Commons license, and indicate if changes were made. The images or other third party material in this article are included in the article's Creative Commons license, unless indicated otherwise in a credit line to the material. If material is not included in the article's Creative Commons license and your intended use is not permitted by statutory regulation or exceeds the permitted use, you will need to obtain permission directly from the copyright holder. To view a copy of this license, visit http://creativecommons. org/licenses/by/4.0/.

\section{References}

1. Hogendoorn PCW, Bovee JVMG. GPN. Chondrosarcoma (grades I-III), including primary and secondary variants and periosteal chondrosarcoma. In: Fletcher CDM, Bridge JA, Hogendoorn PCW, Mertens F, editors. WHO classification of tumours of soft tissue and bone. 4th ed. Lyon: IARC Press; 2013. p. 264-8.

2. Italiano A, Mir O, Cioffi A, Palmerini E, Piperno-Neumann S, Perrin C, et al. Advanced chondrosarcomas: Role of chemotherapy and survival. Ann Oncol. 2013;24:2916-22.

3. Andreou D, Ruppin S, Fehlberg S, Pink D, Werner M, Tunn PU. Survival and prognostic factors in chondrosarcoma: Results in 115 patients with long-term follow-up. Acta Orthop. 2011;82:749-55.

4. Streitbuerger A, Ahrens H, Gosheger G, Henrichs M, Balke M, Dieckmann $\mathrm{R}$, et al. The treatment of locally recurrent chondrosarcoma: Is extensive further surgery justified? Bone Jt J. 2012;94-B:122-7.

5. Mitchell AD, Ayoub K, Mangham DC, Grimer RJ, Carter SR, Tillman RM. Experience in the treatment of dedifferentiated chondrosarcoma. Bone Jt J. 2000;82:55-61.

6. Giuffrida AY, Burgueno JE, Koniaris LG, Gutierrez JC, Duncan R, Scully SP. Chondrosarcoma in the United States (1973 to 2003): An analysis of 2890 cases from the SEER database. J Bone Jt Surg Am. 2009;91:1063-72.

7. Mardis ER, Ding L, Dooling DJ, Larson DE, McLellan MD, Chen $\mathrm{K}$, et al. Recurring mutations found by sequencing an acute myeloid leukemia genome. N Engl J Med. 2009;361:1058-66.

8. Cairns RA, Iqbal J, Kucuk C, De Leval L, Jais J, Parrens M, et al. IDH2 mutations are frequent in angioimmunoblastic T-cell lymphoma. Blood. 2012;119:1901-3.

9. Parsons W, Jones S, Zhang X, Lin JC-H, Leary R, Angenendt P, et al. An integrated genomic analysis of human glioblastoma multiforme. Science (80-). 2008;321:1807-12. 
10. Borger DR, Tanabe KK, Fan KC, Lopez HU, Fantin VR, Straley $\mathrm{KS}$, et al. Frequent mutation of isocitrate dehydrogenase (IDH) 1 and IDH2 in cholangiocarcinoma identified through broad-based tumor genotyping. Oncologist. 2012;17:72-9.

11. Pansuriya TC, Van Eijk R, D’Adamo P, Van Ruler MAJH, Kuijjer ML, Oosting J, et al. Somatic mosaic IDH1 and IDH2 mutations are associated with enchondroma and spindle cell hemangioma in Ollier disease and Maffucci syndrome. Nat Genet. 2011;43:1256-61.

12. Amary MF, Bacsi K, Maggiani F, Damato S, Halai D, Berisha F, et al. IDH1 and IDH2 mutations are frequent events in central chondrosarcoma and central and periosteal chondromas but not in other mesenchymal tumours. J Pathol. 2011;224:334-43.

13. Amary MF, Damato S, Halai D, Eskandarpour M, Berisha F, Bonar F, et al. Ollier disease and Maffucci syndrome are caused by somatic mosaic mutations of IDH1 and IDH2. Nat Genet. 2011;43:1262-5.

14. Hirata M, Sasaki M, Cairns RA, Inoue S, Puviindran V, Li WY, et al. Mutant IDH is sufficient to initiate enchondromatosis in mice. Proc Natl Acad Sci. 2015;112:2829-34.

15. Jin Y, Elalaf H, Watanabe M, Tamaki S, Hineno S, Matsunaga K, et al. Mutant IDH1 dysregulates the differentiation of mesenchymal stem cells in association with gene-specific histone modifications to cartilage- and bone-related genes. PLoS ONE 2015;10:e0131998.

16. Ward PS, Patel J, Wise DR, Abdel-Wahab O, Bennett BD, Coller $\mathrm{HA}$, et al. The common feature of leukemia-associated IDH1 and IDH2 mutations is a neomorphic enzyme activity converting $\alpha$ ketoglutarate to 2-hydroxyglutarate. Cancer Cell. 2010;17:225-34.

17. Figueroa ME, Abdel-Wahab O, Lu C, Ward PS, Patel J, Shih A, et al. Leukemic IDH1 and IDH2 mutations result in a hypermethylation phenotype, disrupt tet 2 function, and impair hematopoietic differentiation. Cancer Cell. 2010;18:553-67.

18. Chowdhury R, Yeoh KK, Tian Y-M, Hillringhaus L, Bagg EA, Rose NR, et al. The oncometabolite 2-hydroxyglutarate inhibits histone lysine demethylases. EMBO Rep. 2011;12:463-9.

19. Xu W, Yang H, Liu Y, Yang Y, Wang P, Kim S-H, et al. Oncometabolite 2-hydroxyglutarate is a competitive inhibitor of $\alpha$-ketoglutarate-dependent dioxygenases. Cancer Cell. 2011;19:17-30.

20. Koivunen P, Lee S, Duncan CG, Lopez G, Lu G, Ramkissoon S, et al. Transformation by the $(\mathrm{R})$ enantiomer of 2-hydroxyglutarate linked to EGLN activation. Nature. 2012;483:484-8.

21. Lu C, Ward PS, Kapoor GS, Rohle D, Turcan S, Abdel-Wahab O, et al. IDH mutation impairs histone demethylation and results in a block to cell differentiation. Nature. 2012;483:474-8.

22. Sasaki M, Knobbe CB, Itsumi M, Elia AJ, Harris IS, Chio IIC, et al. D-2-hydroxyglutarate produced by mutant Idh1 perturbs collagen maturation and basement membrane function. Genes Dev. 2012;26:2038-49.

23. Zhao S, Lin Y, Xu W, Jiang W, Zha Z, Wang P, et al. Gliomaderived mutations in IDH1 dominantly inhibit IDH1 catalytic activity and induce HIF-1 $\alpha$. Science (80-). 2009;324:261-5.

24. Losman J, Looper R, Koivunen P, Lee S, Rebekka K, Mcmahon $\mathrm{C}$, et al. R)-2-hydroxyglutarate is sufficient to promote leukemogenesis and its effects are reversible. Science (80-). 2013;339:1621-5.

25. Lu C, Venneti S, Akalin A, Fang F, Ward PS, DeMatteo RG, et al. Induction of sarcomas by mutant IDH2. Genes Dev 2013;27:1986-98.

26. Ogawara Y, Katsumoto T, Aikawa Y, Shima Y, Kagiyama Y, Soga T, et al. IDH2 and NPM1 mutations cooperate to activate Hoxa9/Meis1 and hypoxia pathways in acute myeloid Leukemia. Cancer Res. 2015;75:2005-16.

27. Suijker J, Oosting J, Koornneef A, Struys EA, Gajja S, Schaap FG, et al. Inhibition of mutant IDH1 decreases D-2-HG levels without affecting tumorigenic properties of chondrosarcoma cell lines. Oncotarget. 2015;6:12505-19.

28. Li L, Paz AC, Wilky BA, Johnson B, Galoian K, Rosenberg A, et al. Treatment with a small molecule mutant idh1 inhibitor suppresses tumorigenic activity and decreases production of the oncometabolite 2-hydroxyglutarate in human chondrosarcoma cells. PLoS ONE 2015;10:e0133813.

29. Rohle D, Popovici-muller J, Palaskas N, Turcan S, Campos C, Tsoi J, et al. An inhibitor of mutant IDH1 delays growth and promotes differentiation of glioma cells. Science (80-). 2013;340:626-30.

30. Pusch S, Krausert S, Fischer V, Balss J, Ott M, Schrimpf D, et al. Pan-mutant IDH1 inhibitor BAY 1436032 for effective treatment of IDH1 mutant astrocytoma in vivo. Acta Neuropathol. 2017;133:629-44.

31. Yen K, Travins J, Wang F, David MD, Artin E, Straley K, et al. AG-221, a first-in-class therapy targeting acute myeloid leukemia harboring oncogenic IDH2 mutations. Cancer Discov. 2017;7:478-93.

32. Stein EM, Dinardo CD, Pollyea DA, Fathi AT, Roboz GJ, Altman $\mathrm{JK}$, et al. Enasidenib in mutant-IDH2 relapsed or refractory acute myeloid leukemia. Blood. 2017;130:722-32.

33. Amatangelo MD, Quek L, Shih A, Stein EM, Roshal M, David $\mathrm{MD}$, et al. Enasidenib induces acute myeloid leukemia cell differentiation to promote clinical response. Blood. 2017;130:732-42.

34. Pollack SM, Jones RL, Lee A, Karavasilis V, Huang PH, Polychronidou G. Novel therapeutic approaches in chondrosarcoma. Future Oncol. 2017;13:637-48.

35. Perut F, Sbrana FV, Avnet S, De Milito A, Baldini N. Spheroidbased 3D cell cultures identify salinomycin as a promising drug for the treatment of chondrosarcoma. J Orthop Res. 2018;36:2305-12.

36. van Oosterwijk JG, de Jong D, van Ruler MA, Hogendoorn PC, Dijkstra PS, van Rijswijk CS, et al. Three new chondrosarcoma cell lines: one grade III conventional central chondrosarcoma and two dedifferentiated chondrosarcomas of bone. BMC Cancer. 2012;12:375.

37. Clark JC, Akiyama T, Dass CR, Choong PF. New clinically relevant, orthotopic mouse models of human chondrosarcoma with spontaneous metastasis. Cancer Cell Int. 2010;10:20.

38. van der Graaf WT, Blay J-Y, Chawla SP, Kim D-W, Bui-Nguyen B, Casali PG, et al. Pazopanib for metastatic soft-tissue sarcoma (PALETTE): a randomised, double-blind, placebo-controlled phase 3 trial. Lancet 2012;379:1879-86.

39. Kawai A, Araki N, Sugiura H, Ueda T, Yonemoto T, Takahashi $\mathrm{M}$, et al. Trabectedin monotherapy after standard chemotherapy versus best supportive care in patients with advanced, translocation-related sarcoma: a randomised, open-label, phase 2 study. Lancet Oncol. 2015;16:406-16.

40. Schöffski P, Chawla S, Maki RG, Italiano A, Gelderblom H, Choy $\mathrm{E}$, et al. Eribulin versus dacarbazine in previously treated patients with advanced liposarcoma or leiomyosarcoma: a randomised, open-label, multicentre, phase 3 trial. Lancet. 2016;387:1629-37.

41. Tap WD, Jones RL, Van Tine BA, Chmielowski B, Elias AD, Adkins $\mathrm{D}$, et al. Olaratumab and doxorubicin versus doxorubicin alone for treatment of soft-tissue sarcoma: an open-label phase $1 \mathrm{~b}$ and randomised phase 2 trial. Lancet. 2016;388:488-97.

42. Endo M, De Graaff MA, Ingram DR, Lim S, Lev DC, Briaire-De Bruijn IH, et al. NY-ESO-1 (CTAG1B) expression in mesenchymal tumors. Mod Pathol. 2015;28:587-95.

43. Pollack SM, Lu H, Gnjatic S, Somaiah N, O'Malley RB, Jones RL, et al. First-in-human treatment with a dendritic cell-targeting lentiviral vector-expressing NY-ESO-1, LV305, induces deep, durable response in refractory metastatic synovial sarcoma patient. J Immunother. 2017;40:302-6. 
44. Pollack SM, Ingham M, Spraker MB, Schwartz GK. Emerging targeted and immune-based therapies in sarcoma. J Clin Oncol. 2018;36:125-35.

45. Tawbi HA, Burgess M, Bolejack V, Van Tine BA, Schuetze SM, $\mathrm{Hu}$ J, et al. Pembrolizumab in advanced soft-tissue sarcoma and bone sarcoma (SARC028): a multicentre, two-cohort, single-arm, open-label, phase 2 trial. Lancet Oncol. 2017;18:1493-501.
46. Ghert MA, Jung ST, Qi W, Harrelson JM, Erickson HP, Block JA, et al. The clinical significance of tenascin-C splice variant expression in chondrosarcoma. Oncology. 2001;61:306-14.

47. Kudo N, Ogose A, Hotta T, Kawashima H, Gu W, Umezu H. et al. Establishment of novel human dedifferentiated chondrosarcoma cell line with osteoblastic differentiation. Virchows Arch. 2007;451:691-9. 